\title{
OPEN Author Correction: Notch signaling pathway is a potential therapeutic target for extracranial vascular malformations
}

\author{
Reema B. Davis, Kristy Pahl, Nicholas C. Datto, Scott V. Smith, Carrie Shawber, \\ Kathleen M. Caron \& Julie Blatt
}

Correction to: Scientific Reports https://doi.org/10.1038/s41598-018-36628-1, published online 20 December 2018

This Article contains errors. In Figure 5c and 5d, the concentrations provided are incorrect; the correct Figure 5 appears below as Figure 1.

A

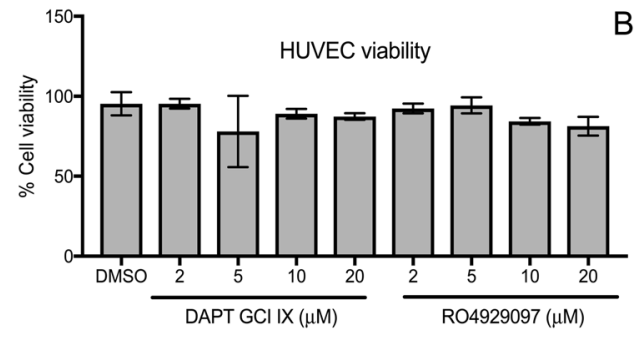

C

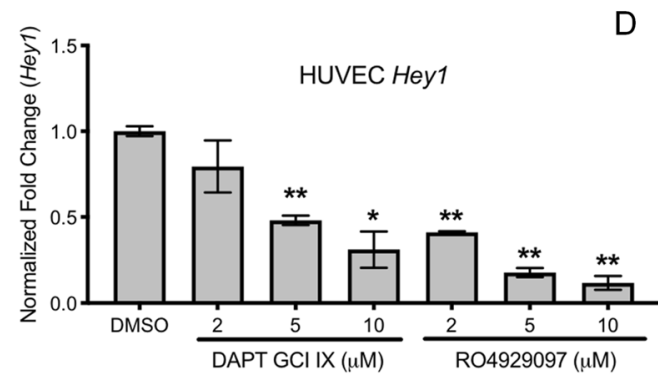

B
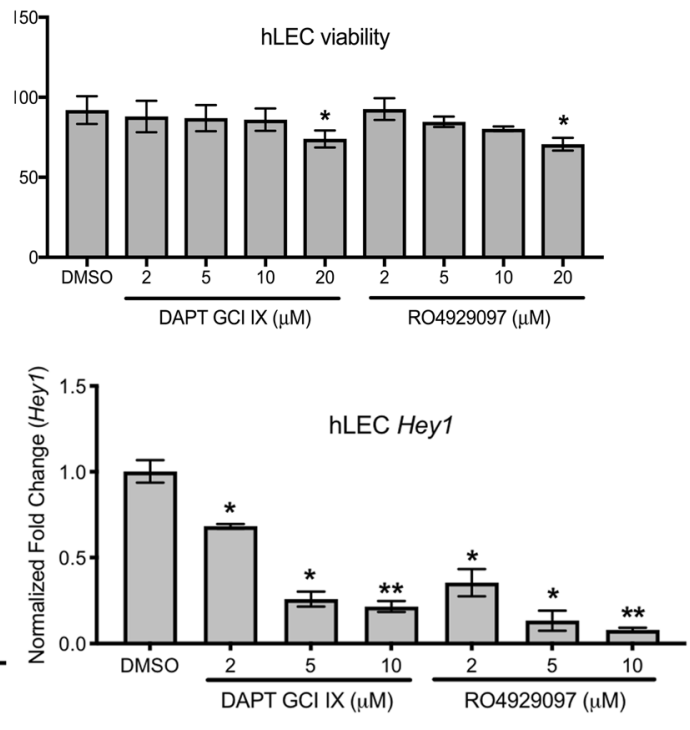

Figure 1. DAPT and RO4929097 effectively inhibit Notch signaling without altering cell viability. (A,B) Measurement of HUVEC (A) and hLEC (B) cell viability after GSI treatments. Quantitative data are represented as mean \pm SEM. $n=3$ for HUVEC and hLEC. Significance was determined by 2 -tailed, type 2 Student's test, $* P<0.05$. (C,D) Relative expression of downstream Notch target gene Hey1 in GSI-treated HUVEC (C) and hLEC (D). Quantitative data are represented as mean values of fold change over DMSO control \pm SEM. $n=$ 4 for each cell line. Gapdh and $\beta$-actin were used as housekeeping control. Significance was determined by 2-tailed, type 2 Student's $t$ test, $* P<0.05, * * P<0.01$. 
In Figure 6, several duplicate images were inadvertently introduced, and the concentrations listed are incorrect. A re-analyzed and re-assembled Figure 6, with the correct information, is provided below as Figure 2.
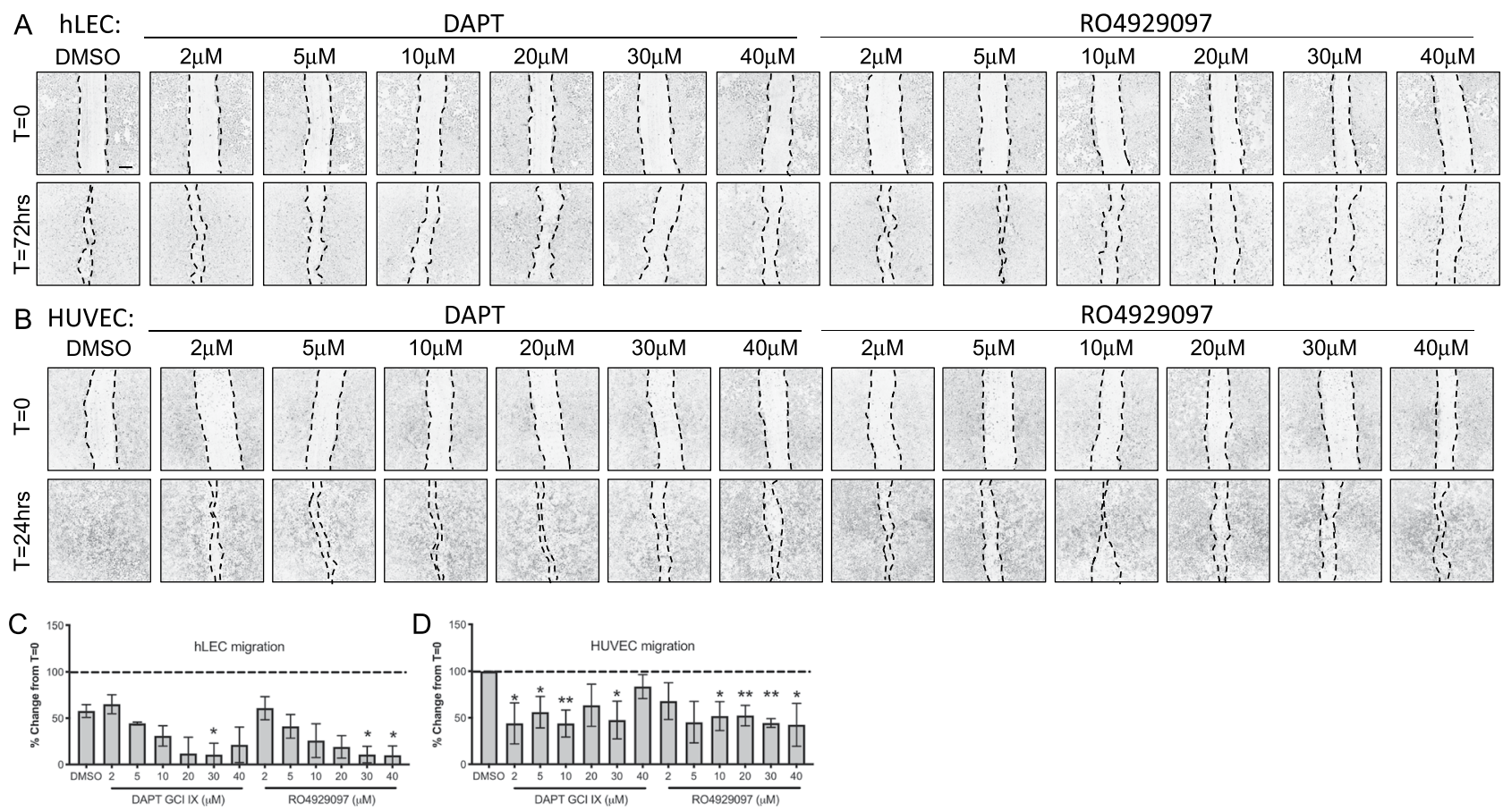

DAPT

R04929097
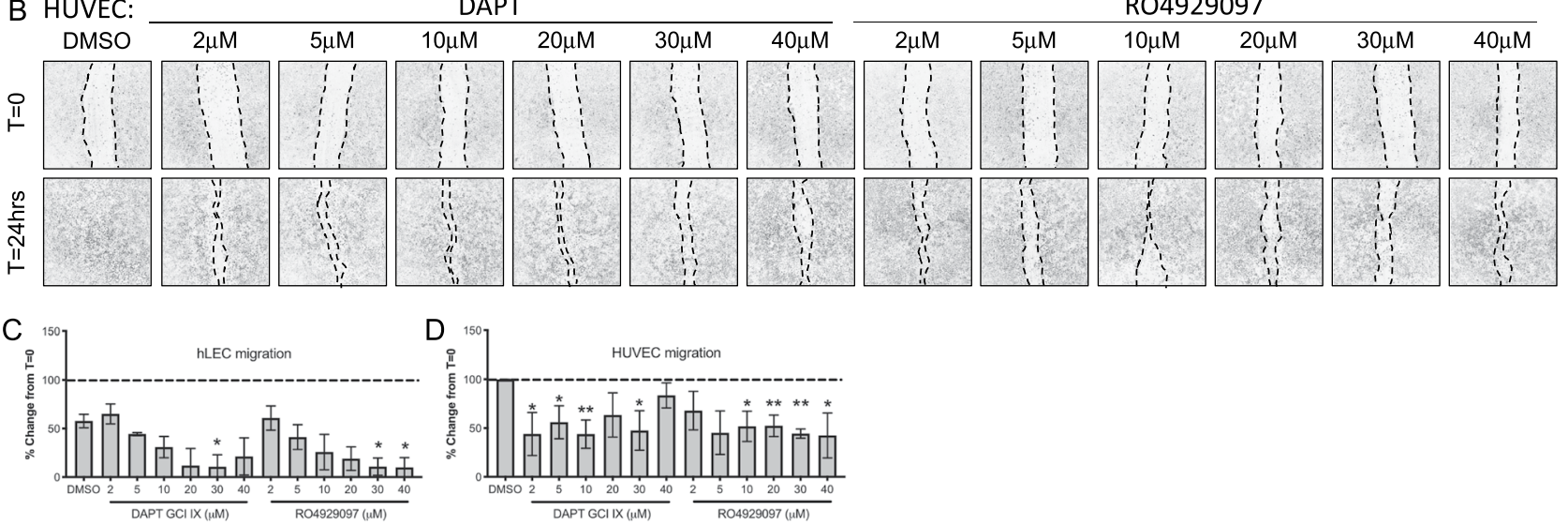

Figure 2. GSIs block cellular migration (A,B) Control DMSO or GSI treated hLEC (A) at 72 hrs and HUVEC (B) at $24 \mathrm{hrs}$ post-scratch. (C,D) Migration from the time of scratch $(\mathrm{T}=0)$ for hLEC $(\mathbf{C})$ and HUVEC (D) was measured. Quantitative data are represented as mean \pm SEM. $n=4$ for HUVEC and $n=3$ for hLEC. Significance was determined by 2 -tailed, type 2 Student's t test, $* P<0.05, * * P<0.01$. Scale bar, $200 \mu \mathrm{M}$.

As a result, in the Results section under subheading " $\gamma$-secretase inhibitors can effectively inhibit angiogenesis of both human blood and lymphatic cultured endothelial cells",

" $8 \mu \mathrm{M}$ of DAPT reduced hLEC migration to about 50\% and HUVEC migration to about 35\% while RO4929097 was more effective at $6 \mu \mathrm{M}$ in both cell types (Fig. 6C,D)".

should read:

" $30 \mu \mathrm{M}$ of DAPT reduced hLEC migration by $90 \%$ and HUVEC migration by about $50 \%$; HUVEC migration was significantly reduced at $2 \mu \mathrm{M}$. RO4929097 had significant effect on hLEC starting $30 \mu \mathrm{M}$ and $10 \mu \mathrm{M}$ on HUVECs (Fig. 6C,D)".

And, under subheading "DAPT and RO4929097downregulate Heyl expression in blood and lymphatic endothelial cells without altering human cell viability",

"DAPT downregulated Hey1 expression in HUVECs beginning at $4 \mu \mathrm{M}$, while $2 \mu \mathrm{M}$ of RO4929097 was sufficient to downregulate Heyl (Fig. 5C)".

should read:

"DAPT downregulated Hey1 expression in HUVECs beginning at $5 \mu \mathrm{M}$, while $2 \mu \mathrm{M}$ of RO4929097 was sufficient to downregulate Heyl (Fig. 5C)".

In addition, there are the following typographical errors in the Results section under subheading "DAPT and RO4929097downregulate Heyl expression in blood and lymphatic endothelial cells without altering human cell viability",

"Neither drug altered HUVEC cell viability at any of the concentrations tested (Fig. 5B)"

should read: 
"Neither drug altered HUVEC cell viability at any of the concentrations tested (Fig. 5A)"

And, in the same section:

" $20 \mu \mathrm{M}$ of DAPT and RO4929097 reduced hLEC viability by almost 30\% without significant changes observed at lower concentrations (Fig. 5A)"

should read:

" $20 \mu \mathrm{M}$ of DAPT and RO4929097 reduced hLEC viability by almost $30 \%$ without significant changes observed at lower concentrations (Fig. 5B)"

Finally, in the Methods section, under subheading "Cell viability",

"Graded concentrations [2, 4, 6, 8, 10, 20 MM] of DAPT (Selleckchem, S2215) or RO4929097 (Selleckchem, S1575) [2-20 uM] for 24-72 hours."

should read:

"Graded concentrations [2-20 $\mu \mathrm{M}$ ] of DAPT (Selleckchem, S2215) or RO4929097 (Selleckchem, S1575) $[2-20 \mu \mathrm{M}]$ for $24-72$ hours".

And under the subheading "Scratch migration assay",

"After scratching, the wells were rinsed with 1XPBS to remove non-adherent cells and then treated with control DMSO or increasing concentrations $[2,4,6,8,10,20 \mu \mathrm{M}]$ of DAPT or RO4929097"

should read:

"After scratching, the wells were rinsed with 1XPBS to remove non-adherent cells and then treated with control DMSO or increasing concentrations $[2,5,10,20,30,40 \mu \mathrm{M}]$ of DAPT or RO4929097"

The main conclusions of the Article are unaffected by these changes.

(c) (i)

Open Access This article is licensed under a Creative Commons Attribution 4.0 International License, which permits use, sharing, adaptation, distribution and reproduction in any medium or format, as long as you give appropriate credit to the original author(s) and the source, provide a link to the Creative Commons license, and indicate if changes were made. The images or other third party material in this article are included in the article's Creative Commons license, unless indicated otherwise in a credit line to the material. If material is not included in the article's Creative Commons license and your intended use is not permitted by statutory regulation or exceeds the permitted use, you will need to obtain permission directly from the copyright holder. To view a copy of this license, visit http://creativecommons.org/licenses/by/4.0/.

(C) The Author(s) 2020 